University of Nebraska - Lincoln

DigitalCommons@University of Nebraska - Lincoln

\title{
Physiological responses of resistant and susceptible barley, Hordeum vulgare to the Russian wheat aphid, Diurpahis noxia (Mordvilko)
}

\author{
Andrea R. Gutsche \\ University of Nebraska - Lincoln \\ Tiffany M. Heng-Moss \\ University of Nebraska-Lincoln, thengmoss2@unl.edu \\ Leon G. Higley \\ University of Nebraska-Lincoln, Ihigley1@unl.edu \\ Gautam Sarath \\ University of Nebraska - Lincoln, Gautam.sarath@ars.usda.gov \\ Dolores W. Mornhinweg \\ USDA-ARS, do.mornhinweg@ars.usda.gov
}

Follow this and additional works at: https://digitalcommons.unl.edu/biochemistrysarath

Part of the Biochemistry, Biophysics, and Structural Biology Commons

Gutsche, Andrea R.; Heng-Moss, Tiffany M.; Higley, Leon G.; Sarath, Gautam; and Mornhinweg, Dolores W., "Physiological responses of resistant and susceptible barley, Hordeum vulgare to the Russian wheat aphid, Diurpahis noxia (Mordvilko)" (2009). Gautam Sarath Publications. 8.

https://digitalcommons.unl.edu/biochemistrysarath/8

This Article is brought to you for free and open access by the Biochemistry, Department of at DigitalCommons@University of Nebraska - Lincoln. It has been accepted for inclusion in Gautam Sarath Publications by an authorized administrator of DigitalCommons@University of Nebraska - Lincoln. 


\title{
Physiological responses of resistant and susceptible barley, Hordeum vulgare to the Russian wheat aphid, Diurpahis noxia (Mordvilko)
}

\author{
Andrea R. Gutsche · Tiffany M. Heng-Moss • \\ Leon G. Higley · Gautam Sarath · \\ Dolores W. Mornhinweg
}

Received: 4 February 2009/ Accepted: 3 June 2009

(C) Springer Science+Business Media B.V. 2009

\begin{abstract}
Knowledge of the physiological responses of barley, Hordeum vulgare L., to the Russian wheat aphid, Diuraphis noxia (Mordvilko) (Hemiptera: Aphididae) is critical to understanding the defense response of barley to aphid injury and identifying resistance mechanisms. This study documented the impact of $D$. noxia feeding on resistant ('Sidney') and susceptible ('Otis') barley through chlorophyll fluorescence measurements, chlorophyll content, and carbon assimilation $\left(\mathrm{A}-\mathrm{C}_{\mathrm{i}}\right)$ curves recorded at 1 , $3,6,10$, and 13 days after aphid introduction. All chlorophyll fluorescence parameters evaluated were similar between aphid-infested and control plants for both cultivars. A- $\mathrm{C}_{\mathrm{i}}$ curves showed that $D$. noxia feeding negatively impacts the photosynthetic capacity in both cultivars, but this effect was greater in the susceptible plants. From the A- $\mathrm{C}_{\mathrm{i}}$ curves, it is apparent that compensation occurs in resistant barley by day 10 , but by the conclusion of the experiment, aphid populations reached levels that overwhelmed the resistant barley seedlings. Differences observed in carbon assimilation curves between control and infested plants show that $D$. noxia feeding impacts the dark reaction, specifically rubisco activity and RuBP regeneration. It is likely that declines in the photochemical efficiency and chlorophyll content of the plants may be a
\end{abstract}

Handling Editor: Robert Glinwood

A. R. Gutsche · T. M. Heng-Moss ( $₫)$ · L. G. Higley

Department of Entomology, University of Nebraska, Lincoln,

NE 68583, USA

e-mail: thengmoss2@unl.edu

G. Sarath

USDA-ARS, Lincoln, NE 68583, USA

D. W. Mornhinweg

USDA-ARS, Stillwater, OK 74075, USA secondary effect and not the primary trigger of declines in host plant function.

Keywords Plant physiology - Plant resistance . Plant-insect interactions · Gas exchange - Chlorophyll content - Chlorophyll fluorescence

\section{Introduction}

Diuraphis noxia (Mordvilko) (Hemiptera: Aphididae) is a serious pest of wheat, Triticum aestivum L., and barley, Hordeum vulgare L. The original D. noxia biotype has cost American wheat and barley producers billions of dollars in losses since it first appeared in the United States in 1986 (Pons 2004). These aphids prefer to feed within the leaf whorl and on new leaves (Macedo et al. 2003), which are strong sinks for phloem-mobile mineral nutrients, amino compounds, and carbohydrates. Damage symptoms include chlorotic leaf streaking and leaf rolling (Burd and Burton 1992). Leaf rolling is doubly damaging to host plants as it reduces photosynthetic area and provides an optimum environment for aphid reproduction. Leaf rolling also plays an important role in the effectiveness of certain management strategies, as it prevents the contact of insecticides and biological control agents with the aphids.

Because of the limited effectiveness of chemical and biological control methods, plant resistance is viewed as a viable approach (Webster and Kenkel 1999). Diuraphis noxia-resistant sources of barley have been identified (Mornhinweg et al. 1995, 1999, 2006, 2007a, b, 2008), although little is known about the physiological mechanisms that confer resistance.

Understanding how aphid feeding affects plant physiology (e.g. photosynthetic rates and fluorescence parameters) 
may help to explain the physiological mechanisms underlying plant resistance. Considerable progress has been made toward identifying the physiological responses of resistant and susceptible wheat to D. noxia (Burd and Elliott 1996; Franzen et al. 2007; Haile et al. 1999; Heng-Moss et al. 2003; Macedo et al. 2009), however; only limited information is available on the responses of resistant and susceptible barley to aphid feeding (Burd and Elliott 1996; Miller et al. 1994). Research on the physiological responses of resistant and susceptible cereals has focused on several different areas including; chlorophyll and protein content, chlorophyll fluorescence, gas exchange, and molecular pathways.

Several studies have reported that resistant and susceptible plants exhibit differences in chlorophyll maintenance in response to $D$. noxia feeding. Susceptible plants experience alterations in chlorophyll content ( $\mathrm{Ni}$ et al. 2002) such as chlorosis development, reductions in chlorophyll ( $a$ and $b$ ) and carotenoids, and changes in chlorophyll fluorescence (Burd and Elliott 1996; Franzen et al. 2007; Heng-Moss et al. 2003; Miller et al. 1994; Rafi et al. 1997). In contrast, resistant plants have been shown to exhibit minimal differences in chlorophyll maintenance in response to D. noxia feeding (Burd and Elliott 1996; Franzen et al. 2007; Miller et al. 1994).

Differences in chlorophyll fluorescence and photosynthesis also exist between resistant and susceptible cereals. Haile et al. (1999) found that D. noxia-infested resistant and susceptible wheat plants had reduced chlorophyll fluorescence and photosynthetic rates when compared to control plants. After the aphids were removed ( 7 days after aphid introduction), the tolerant cultivar showed a complete recovery of photosynthetic capacity by 7 days after aphid removal, while photosynthetic recovery was not observed in the susceptible or antibiotic cultivars. Macedo et al. (2003) also found that D. noxia feeding caused reductions in photosynthesis and chlorophyll fluorescence for susceptible wheat, but only under continuous light. Under $72 \mathrm{~h}$ of continuous dark, aphid feeding did not cause damage symptom formation or reductions in gas exchange. This work demonstrates that the development of $D$. noxia damage symptoms on susceptible wheat seedlings may be a light-activated process even though the origin of the damage symptoms is aphid feeding.

Miller et al. (1994) used barley to examine chlorophyll fluorescence and stomatal resistance in response to $D$. noxia feeding. No significant differences were observed in the effectiveness of photosystem II between infestedresistant and -susceptible barley genotypes. Diuraphis noxia feeding did lead to closure of the stomates, but no differences were detected in stomatal closure between resistant and susceptible plants. Burd and Elliott (1996) examined chlorophyll fluorescence changes in resistant and susceptible wheat and barley in response to D. noxia infestation. In contrast, Miller et al. (1994) and Burd and Elliott (1996) found that photochemical efficiency was significantly decreased in the infested susceptible wheat and barley plants. However, declines were not observed in the resistant infested plants. Burd and Elliott (1996) concluded that wheat and barley exhibit similar responses to D. noxia feeding.

The most recent studies on the physiological responses of resistant and susceptible cereal to $D$. noxia were conducted by Franzen et al. (2007) and Macedo et al. (2009). Franzen et al. (2007) found that resistant wheat plants infested with D. noxia had photosynthetic rates similar to or greater than those of control plants, while susceptible-infested plants showed accelerated declines in photosynthesis. Measurements over time showed that infested-resistant plants had delays in photosynthetic senescence. Results from this study suggest that resistant plants subjected to $D$. noxia feeding compensated for aphid injury by altering their senescence pathways, while susceptible plants appeared to have accelerated senescence. Macedo et al. (2009) examined the impact of feeding injury by $D$. noxia and the nonsymptomatic aphid, Rhopalosiphum padi on susceptible and resistant wheat. Photosynthetic measurements indicated that feeding by both $D$. noxia and $R$. padi caused reductions in photosynthetic activity and that these initial reductions are likely related to stomatal limitation or $\mathrm{CO}_{2}$ uptake (Rafi et al. 1996 and Franzen et al. 2007).

The studies outlined have provided insights into differential responses between resistant and susceptible plants; however, relatively few studies have focused on how D. noxia feeding impacts the physiological responses of resistant and susceptible barley and the possible role of changes in photosynthesis and fluorescence as a mechanism for plant resistance. The objectives of this research were to document the physiological responses of resistant and susceptible barley to $D$. noxia over time and investigate photosynthetic processes as a mechanism for plant resistance to insect injury. The impact $D$. noxia had on resistant and susceptible plants was measured by examining number of aphids, chlorophyll content, photosynthetic responses, and chlorophyll fluorescence kinetics.

\section{Materials and methods}

Plant material and insects

Seeds of the susceptible barley cultivar 'Otis' and resistant cultivar 'Sidney' were planted in 'SC-10 Super Cell' Conetainers ${ }^{\circledR}(3.8 \mathrm{~cm} \times 21 \mathrm{~cm})$ (Stuewe \& Sons, Inc. Corvallis, OR) containing a mixture of sand-soil-peat-perlite 
(0.66:0.33:1:1). 'Sidney' (previously known as experimental line 98BX 28-58B) was developed through modified backcross breeding of Russian wheat aphid-resistant STARS 9301B into Otis. Three seeds of each cultivar were planted in a Cone-tainer ${ }^{\circledR}$ to a depth of approximately $2 \mathrm{~cm}$ and placed in Cone-tainer $\AA$ racks. The Cone-tainer ${ }^{\circledR}$ racks were placed over a plastic tray $(54 \mathrm{~cm} \times 28 \mathrm{~cm} \times 6 \mathrm{~cm})$ filled with water to ensure that plants were watered uniformly from the bottom. Plants were grown to the four leaf stage (14 days) in a $36-\mathrm{m}^{2}$ greenhouse bay under 400-watt high intensity lamps with a 16:8 (L:D) h photoperiod, a temperature of $27 \pm 3^{\circ} \mathrm{C}$, and $40-50 \%$ relative humidity. Plants were thinned to one plant per Cone-tainer ${ }^{\circledR}$ once seedlings emerged from the soil.

Biotype $1 D$. noxia were obtained from the United States Department of Agriculture-Agricultural Research Service research facility in Stillwater, OK. Aphids were maintained on susceptible 'Morex' barley and were kept in growth chambers (Percival Scientific, Perry, IA) at $21 \pm 1^{\circ} \mathrm{C}$, 40-50\% RH, and a photoperiod of 16:8 (L:D) h.

The experiment utilized a completely randomized design with seven replications. The treatment design was a $2 \times 2 \times 5$ factorial treatment design that included 2 barley cultivars, 2 aphid infestation levels ( 0 and 20 D. noxia), and 5 evaluation dates $(1,3,6,10$, and 13 days after aphid introduction-rain delayed evaluation from 9 to 10 days). Barley plants were randomly designated to be a control plant or an infested plant. At the start of the experiment, ten aphids were introduced onto the first and second leaf blade (total of 20 aphids) of each designated infested plant. Aphids were confined to individual plants using tubular plexiglass cages (4 cm diameter $\times 30 \mathrm{~cm}$ height) with organdy fabric fastened by rubber bands to the top. Control plants were also caged. After aphid introduction, plants were kept in the greenhouse until each respective evaluation date.

Plants were evaluated for leaf chlorosis on each evaluation date using a 1-9 scale, where $1=$ plants appear healthy and $9=$ plant death or no recovery possible (Webster et al. 1991). The total number of D. noxia on infested plants was assessed through direct counting before aphid removal at each evaluation date.

\section{Physiological responses of barley to D. noxia}

\section{Chlorophyll concentration}

Chlorophyll levels were measured for each treatment from leaves of seven different plants (replicates) at 3 locations (near the base, the middle, and the tip of the leaf) on the first and second leaf blades at each evaluation interval using a chlorophyll meter (Model Spad-502, Minolta Camera Co., Osaka, Japan). The arithmetic mean of these measurements was used for all subsequent analyses.

\section{Gas exchange responses}

Photosynthetic responses were recorded at 3, 6, 10, and 13 days after aphid introduction (rain delayed evaluation from 9 to 10 days) using a portable photosynthesis system (model LI-6400, LI-COR, Lincoln, NE). Although plants were maintained in a greenhouse, measurements were performed o utdoors after plants had acclimatized for $>1 \mathrm{~h}$. Photosynthetic measurements included: assimilation rate (A) versus intercellular $\mathrm{CO}_{2}$ concentration measurements (A- $\mathrm{C}_{\mathrm{i}}$ curves), where rates were measured at $1,400 \mu \mathrm{mol}$ photons $\mathrm{m}^{-2} \mathrm{~s}^{-1}$ light intensity and $\mathrm{CO}_{2}$ concentrations ranging from 50 to $1000 \mathrm{ppm}$. $\mathrm{A}-\mathrm{C}_{\mathrm{i}}$ response curves were determined by the automated programs of the LI- 6400 .

Calculations of the stomatal and non-stomatal components of photosynthesis were made using the methods described by Farquhar and Sharkey (1982). By comparing $A$ at a $C_{i}$ of $400 \mu 1^{-1} \mathrm{CO}_{2}$ to $A$ at the $C_{i}$ corresponding to an intracellular $\mathrm{CO}_{2}\left(\mathrm{C}_{\mathrm{a}}\right)$ of $400 \mu \mathrm{ll}^{-1} \mathrm{CO}_{2}$, the stomatal limitation (SL) to photosynthesis can be calculated (Ryan et al. 1987).

The $A$ versus $C_{i}$ response curve can also be used to determine the $\mathrm{CO}_{2}$ compensation point (the $\mathrm{C}_{\mathrm{i}}$ value where $\mathrm{A}=0$, given in $\mathrm{Pa}$ ), carboxylation efficiency ( $\mathrm{CE}$, the slope of the linear portion of the $A$ versus $C_{i}$ response curve), and changes in net $\mathrm{CO}_{2}$ assimilation at saturating $\mathrm{C}_{\mathrm{i}}$ $\left(A_{\max }\right)$. Analyses of the $\mathrm{A}-\mathrm{C}_{\mathrm{i}}$ curves also allow for determination of maximum carboxylation velocity of rubisco $\left(\mathrm{V}_{\mathrm{cmax}}\right.$-determined from the linear portion of the curve, $\mu \mathrm{mol} \mathrm{CO}_{2} \mathrm{~m}^{-2} \mathrm{~s}^{-1}$ ) and maximum potential rate of electron transport contributing to ribulose-1,5-bisphosphate (RuBP) regeneration $\left(\mathrm{J}_{\max }-\mu \mathrm{mol}\right.$ electrons $\left.\mathrm{m}^{-2} \mathrm{~s}^{-1}\right)$. These values were calculated using the Photosyn Assistant Software (Dundee Scientific, Scotland, UK). For each treatment, response curves from leaves of three different plants (replications) were measured and estimated for SL, $\mathrm{CE}, \mathrm{CO}_{2}$ compensation point, $\mathrm{A}_{\max }, \mathrm{V}_{\mathrm{cmax}}$, and $\mathrm{J}_{\max }$.

\section{Chlorophyll fluorescence}

Chlorophyll fluorescence was measured at 1, 3, 6, and 10 days after aphid introduction (rain delayed evaluation from 9 to 10 days) using an OS5-FL modulated chlorophyll fluorometer (Opti-Sciences, Tyngsboro, MA). Leaves were dark adapted with clips for at least $30 \mathrm{~min}$ before measurements. Determinations were made of minimum fluorescence for dark-adapted leaves $\left(\mathrm{F}_{\mathrm{o}}\right)$, maximum fluorescence for dark-adapted leaves $\left(\mathrm{F}_{\mathrm{m}}\right)$, fluorescence under steady state conditions $\left(\mathrm{F}_{\mathrm{s}}\right)$, maximal fluorescence under steady state conditions $\left(\mathrm{F}_{\mathrm{ms}}\right)$, quantum yield $\left.\left(\mathrm{Y}=\left(\mathrm{F}_{\mathrm{ms}}-\mathrm{F}_{\mathrm{s}}\right) / \mathrm{F}_{\mathrm{ms}}\right)\right)$, photochemical quenching $(\mathrm{qP}=$ $\left.\left(\mathrm{F}_{\mathrm{ms}}-\mathrm{F}_{\mathrm{s}}\right) /\left(\mathrm{F}_{\mathrm{ms}}-\mathrm{F}_{\mathrm{o}}\right)\right)$, and non-photochemical quenching $\left(\mathrm{qN}=\left(\mathrm{F}_{\mathrm{m}}-\mathrm{F}_{\mathrm{ms}}\right) /\left(\mathrm{F}_{\mathrm{m}}-\mathrm{F}_{\mathrm{o}}\right)\right.$ ) (see OS5-FL Manual for 
additional details). For each treatment, fluorescence parameters from leaves of six different plants (replicates) were measured.

\section{Data analysis}

Mixed model analysis (PROC MIXED, SAS Institute 2002) was conducted for each measurement to detect differences in aphid number, chlorophyll levels, gas-exchange responses, and chlorophyll fluorescence measurements. When appropriate, the means were separated according to Fisher least significant difference (LSD) procedure. Statistical significance was assumed when $P \leq 0.05$.

\section{Results and discussion}

\section{Leaf chlorosis}

Aphid-infested susceptible and resistant plants showed limited visual damage at 1,3 , and 6 days after aphid introduction (data not shown). On days 10 and 13, infested plants of both cultivars (day 10: Susceptible $=2.1 \pm 0.22$, Resistant $=2.1 \pm 0.36$; day 13: Susceptible $=5.7 \pm 0.32$, Resistant $=4.6 \pm 0.27$ ) had significantly higher damage ratings than their respective control plants (day 10: Susceptible $=1.0 \pm 0$, Resistant $=1.0 \pm 0$; day 13: Susceptible $=1.0 \pm 0$, Resistant $=1.0 \pm 0)(\mathrm{F}=28.9, \mathrm{df}=$ $4,120 ; P=0.0001)$. There were no significant differences in visual damage between infested-resistant and -susceptible plants at $1,3,6$, and 10 days (data not shown).

\section{Aphid number}

No significant differences were detected in numbers of aphids between the two barley cultivars at $1,3,6,10$, and 13 days after aphid introduction $(\mathrm{F}=0.4 ; \mathrm{df}=2,60$; $P=0.81$ ) (data not shown). The greatest number of aphids was recorded on the susceptible barley, Otis. The resistant cultivar, Sidney, supported numbers of aphids similar to the susceptible barley throughout the experiment, demonstrating that the resistant genotype was not adversely affecting the biology of the aphids.

\section{Chlorophyll concentration}

Aphid-infested resistant and susceptible plants (first leaf blade) had similar chlorophyll concentrations to control plants on all evaluation dates (data not shown). At days 1, 6 , and 10, aphid infested-resistant and -susceptible plants (second leaf blade) had chlorophyll levels similar to those of their respective control plants (data not shown).
However, on day 13 aphid infested-resistant $(165.5 \pm 14.6)$ and -susceptible plants $(136.0 \pm 21.5)$ had significantly lower chlorophyll levels when compared to their respective control plants (Resistant: 249.9 \pm 31.9 ; Susceptible: $260.7 \pm 13.8$ ) (Resistant: $\mathrm{t}=2.3 ; \mathrm{df}=120 ; P=0.02$; Susceptible: $\mathrm{t}=3.5 ; \mathrm{df}=120 ; P=0.0008$ ). Interestingly, on day 3 the infested-resistant plants $(171.0 \pm 32.1)$ had a significantly lower chlorophyll concentration than resistantcontrol plants $(318.4 \pm 17.6)(\mathrm{t}=4.1 ; \mathrm{df}=120 ; P=$ 0.0001). For all evaluation dates evaluated, there were no significant differences between resistant- and susceptibleinfested plants in the chlorophyll concentrations of the second leaf blade.

\section{Photosynthetic responses}

$\mathrm{A}_{\max }$

Susceptible plants infested with $D$. noxia exhibited declining $\mathrm{A}_{\max }$ values over the course of the experiment with infested plants having lower values when compared to control plants (Figs. 1, 2, 3, and 4). Aphid-infested resistant plants had similar $A_{\max }$ values when compared to control plants at days 3, 6, and 10 (Figs 1, 2, and 3), but by day 13 resistant-infested plants had $\mathrm{A}_{\max }$ values lower than those of control plants (Fig. 4). This research indicates that D. noxia feeding in the susceptible barley is associated with inhibiting the plants' ability to reach its maximum photosynthetic capacity.

\section{Stomatal limitation}

There was a significant aphid effect $(\mathrm{F}=4.5 ; \mathrm{df}=1,30$; $P=0.04$ ), however, stomatal limitation values between aphid treatments of interest were either not significantly different or did not follow an apparent trend (data not shown).

\section{Carboxylation efficiency}

At 3 days after aphid introduction similar declines in CE were documented in the aphid-infested plants of both barley genotypes (Table 1). For the susceptible barley on day 6, CE values of infested plants were similar to control plants (Fig. 2), but by day $10 \mathrm{CE}$ values for the aphidinfested treatment experienced an almost 2 fold decline when compared to control plants (Fig. 3). Conversely, in the resistant barley, CE values of infested plants were slightly lower compared to those of control plants on day 6 (Fig. 2), but by day $10 \mathrm{CE}$ values were similar (Fig. 3). Aphid infestation resulted in lower CE values for resistant 


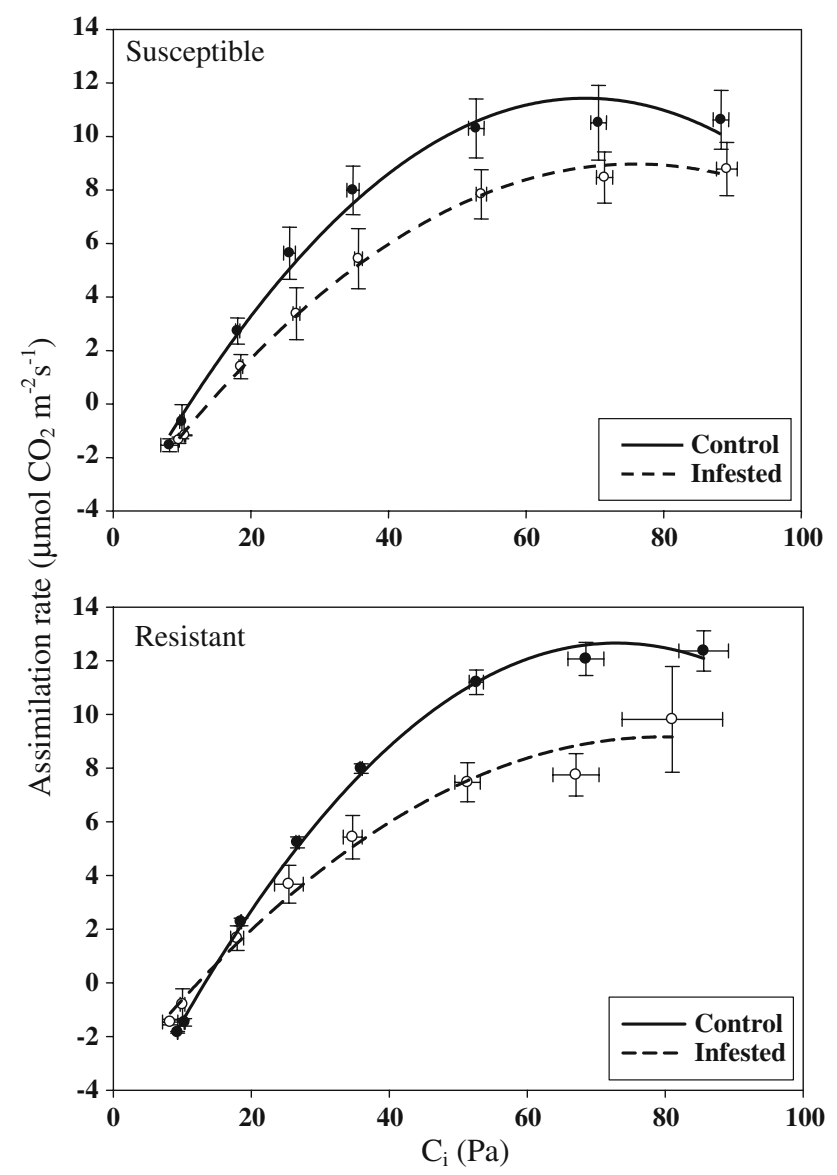

Fig. 1 Assimilation ( $\mu \mathrm{mol} \mathrm{CO}_{2} \mathrm{~m}^{-2} \mathrm{~s}^{-1}$ ) versus intercellular $\mathrm{CO}_{2}$ concentration $(\mathrm{Ci})$ in pascals $(\mathrm{Pa})$ for susceptible and resistant barley at 3 days after aphid introduction

and susceptible plants on day 13, although susceptible plants experienced a more dramatic decline (Fig. 4).

\section{$\mathrm{CO}_{2}$ compensation point}

There was a significant aphid effect $(F=12.98$; df $=1$, 30; $P<0.001)$ which showed that, across days, control plants had lower compensation points than $D$. noxiainfested plants. Infested plants of both cultivars showed $\mathrm{CO}_{2}$ compensation points similar to those of their respective controls at 3, 6, and 10 days after aphid introduction (Figs. 1, 2, and 3). On day 13, aphid infested-resistant and susceptible plants had significantly higher $\mathrm{CO}_{2}$ compensation points when compared to their respective control plants (Resistant: $\mathrm{t}=-5.0 ; \mathrm{df}=32 ; P=0.001$, Susceptible: $\mathrm{t}=-2.0 ; \mathrm{df}=32 ; P=0.05$ ) (Fig. 4). Because the $\mathrm{CO}_{2}$ compensation point represents the level at which oxygen production is zero, plants with lower $\mathrm{CO}_{2}$ compensation points are able to produce oxygen at lower levels of carbon dioxide and, therefore, lower values are expected for the control plants.

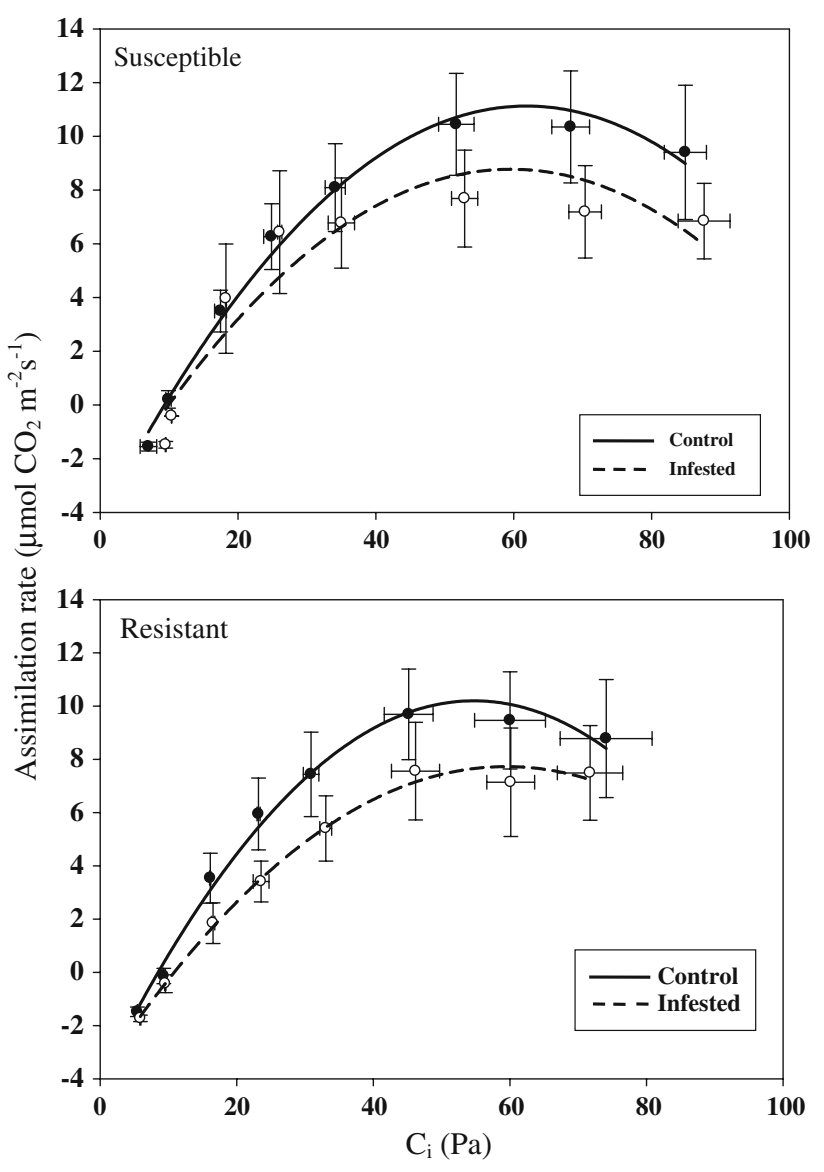

Fig. 2 Assimilation ( $\mu$ mol $\mathrm{CO}_{2} \mathrm{~m}^{-2} \mathrm{~s}^{-1}$ ) versus intercellular $\mathrm{CO}_{2}$ concentration $(\mathrm{Ci})$ in pascals $(\mathrm{Pa})$ for susceptible and resistant barley at 6 days after aphid introduction

$\mathrm{V}_{\mathrm{cmax}}$

Infested plants of both cultivars showed declines in $\mathrm{V}_{\text {cmax }}$ on days 3 and 6 when compared to their respective control plants (Table 1). At day 10 susceptible infested plants showed an almost 2 fold decline in $\mathrm{V}_{\mathrm{cmax}}$ values when compared to control plants. Conversely, resistant infested plants had $\mathrm{V}_{\mathrm{cmax}}$ values similar to those of their control plants on day 10. By 13 days after aphid introduction $\mathrm{V}_{\mathrm{cmax}}$ values for infested plants were significantly lower than the control plants for both cultivars $(\mathrm{F}=31.9$; $\mathrm{df}=1,30$; $P=0.0001$ ) (Table 1). The difference in the responses of the two barley genotypes on day 10 indicates that the plant's ability to reach its maximum rate of rubisco-mediated carboxylation may be a key part of the resistance response.

$\mathrm{J}_{\max }$

Susceptible plants infested with $D$. noxia had declining $J_{\max }$ values over the course of the experiment, with infested plants having lower values when compared to control 


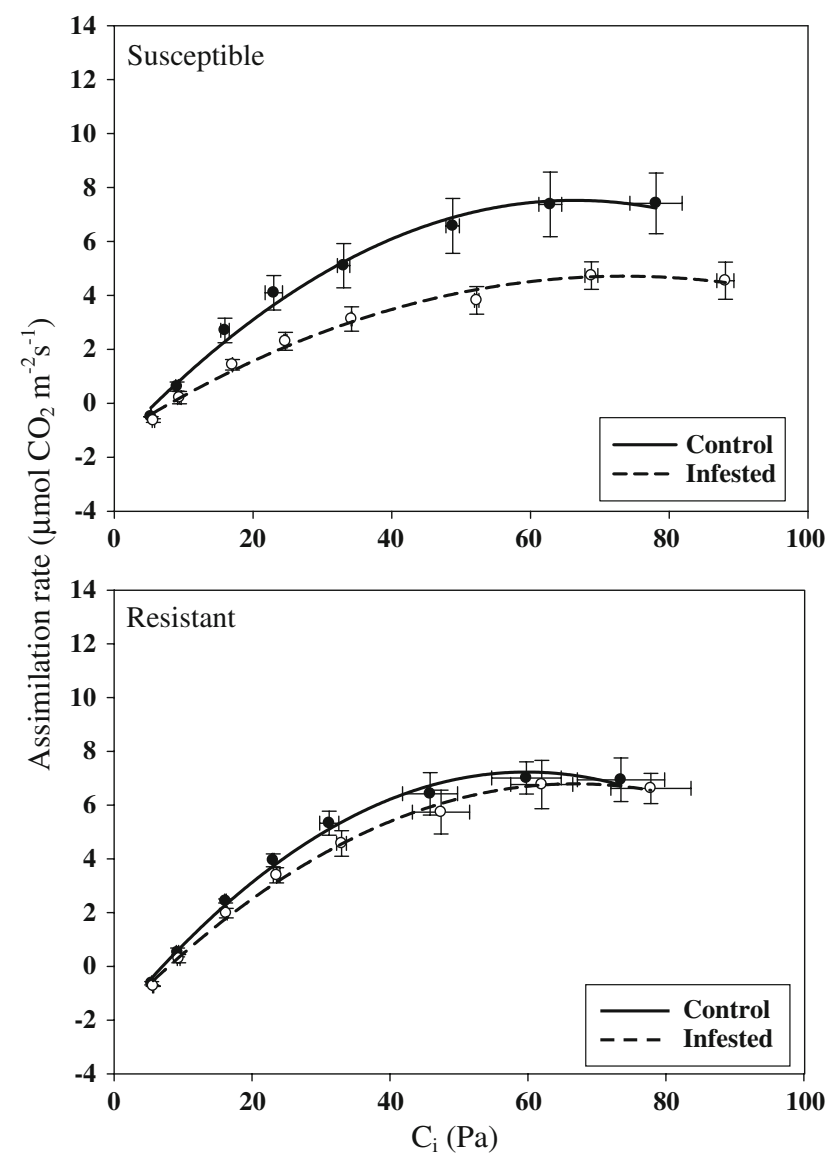

Fig. 3 Assimilation ( $\mu$ mol $\mathrm{CO}_{2} \mathrm{~m}^{-2} \mathrm{~s}^{-1}$ ) versus intercellular $\mathrm{CO}_{2}$ concentration $(\mathrm{Ci})$ in pascals $(\mathrm{Pa})$ for susceptible and resistant barley at 10 days after aphid introduction
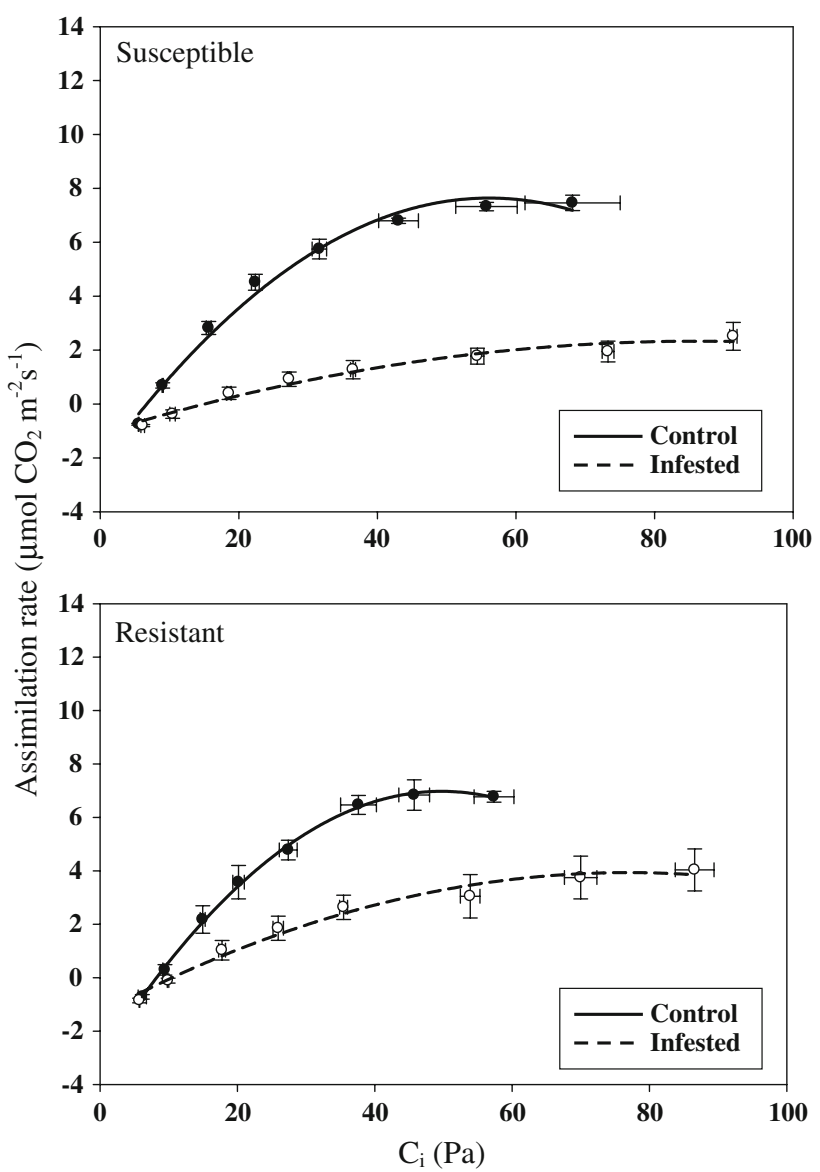

Fig. 4 Assimilation ( $\mu \mathrm{mol} \mathrm{CO}_{2} \mathrm{~m}^{-2} \mathrm{~s}^{-1}$ ) versus intercellular $\mathrm{CO}_{2}$ concentration $(\mathrm{Ci})$ in pascals $(\mathrm{Pa})$ for susceptible and resistant barley at 13 days after aphid introduction

Table 1 Effect of D. noxia on gas-exchange responses of resistant and susceptible barley at 3, 6, 10, and 13 days

\begin{tabular}{|c|c|c|c|c|c|c|c|c|c|}
\hline \multicolumn{10}{|l|}{ Mean $\pm \mathrm{SE}$} \\
\hline & \multicolumn{3}{|l|}{$\mathrm{CE}^{\mathrm{a}}$} & \multicolumn{3}{|l|}{$\mathrm{V}_{\mathrm{cmax}}^{\mathrm{b}}$} & \multicolumn{3}{|l|}{$\mathrm{J}_{\max }^{\mathrm{c}}$} \\
\hline & Control & RWA & $P$ value & Control & RWA & $P$ value & Control & RWA & $P$ value \\
\hline \multicolumn{10}{|l|}{ Day 3} \\
\hline Susceptible & $0.41 \pm 0.06$ & $0.28 \pm 0.08$ & 0.11 & $30.7 \pm 3.47$ & $24.1 \pm 3.66$ & 0.25 & $71.9 \pm 9.58$ & $60.3 \pm 6.76$ & 0.16 \\
\hline Resistant & $0.41 \pm 0.08$ & $0.30 \pm 0.04$ & 0.16 & $33.4 \pm 0.71$ & $22.2 \pm 2.09$ & 0.06 & $85.1 \pm 3.70$ & $58.2 \pm 4.84$ & 0.002 \\
\hline \multicolumn{10}{|l|}{ Day 6} \\
\hline Susceptible & $0.43 \pm 0.08$ & $0.47 \pm 0.13$ & 0.67 & $49.4 \pm 6.76$ & $42.9 \pm 19.2$ & 0.31 & $67.6 \pm 8.18$ & $50.4 \pm 0.50$ & 0.06 \\
\hline Resistant & $0.41 \pm 0.07$ & $0.30 \pm 0.06$ & 0.17 & $39.1 \pm 2.24$ & $33.4 \pm 3.97$ & 0.33 & $58.1 \pm 5.23$ & $47.9 \pm 7.92$ & 0.21 \\
\hline \multicolumn{10}{|l|}{ Day 10} \\
\hline Susceptible & $0.27 \pm 0.05$ & $0.15 \pm 0.09$ & 0.14 & $21.3 \pm 5.13$ & $12.2 \pm 3.86$ & 0.12 & $39.3 \pm 7.88$ & $25.0 \pm 6.95$ & 0.09 \\
\hline Resistant & $0.25 \pm 0.02$ & $0.23 \pm 0.02$ & 0.80 & $20.4 \pm 3.70$ & $17.0 \pm 1.71$ & 0.56 & $39.2 \pm 2.64$ & $37.1 \pm 3.11$ & 0.80 \\
\hline \multicolumn{10}{|l|}{ Day 13} \\
\hline Susceptible & $0.29 \pm 0.03$ & $0.08 \pm 0.01$ & 0.01 & $22.6 \pm 1.64$ & $6.1 \pm 0.89$ & 0.007 & $42.8 \pm 0.32$ & $17.1 \pm 2.70$ & 0.003 \\
\hline Resistant & $0.27 \pm 0.01$ & $0.13 \pm 0.03$ & 0.09 & $22.7 \pm 1.44$ & $9.8 \pm 1.83$ & 0.03 & $42.9 \pm 2.89$ & $22.7 \pm 4.16$ & 0.02 \\
\hline
\end{tabular}

${ }^{a} C E$ Carboxylation efficiency

${ }^{\mathrm{b}} V_{\text {cmax }}$ Maximum Rubisco-mediated carboxylation $\left(\mu \mathrm{mol} \mathrm{CO}_{2} \mathrm{~m}^{-2} \mathrm{~s}^{-1}\right)$

c $J_{\max }$ Maximum potential rate of electron transport contributing to RuBP regeneration ( $\mu \mathrm{mol}$ electron $\mathrm{m}^{-2} \mathrm{~s}^{-1}$ ) 
plants (Table 1). Aphid-infested resistant plants had significantly lower $\mathrm{J}_{\max }$ values when compared to control plants at days 3 and 6 (Figs. 1 and 2), but by day 10 resistant infested plants had $\mathrm{J}_{\max }$ values similar to those of control plants $(\mathrm{F}=30.4$; $\mathrm{df}=1,30 ; P<0.0001)$ (Table 1 and Fig. 3). By day 13 both cultivars showed declines $J_{\max }$ in response to intense aphid pressure (Fig. 4). These results suggest that the tolerance response of the resistant barley may be dependent on alteration of the rate at which RuBP becomes available.

\section{Chlorophyll fluorescence response}

In general, the non-variable minimal fluorescence $\left(\mathrm{F}_{\mathrm{o}}\right)$, the maximal fluorescence $\left(\mathrm{F}_{\mathrm{m}}\right)$, the total amount of variable fluorescence $\left(F_{v}\right)$, and the photochemical efficiency of PSII $\left(\mathrm{F}_{\mathrm{v}} / \mathrm{F}_{\mathrm{m}}\right)$ ratios of both cultivars were not significantly impacted by aphids (data not shown). Similarities in the chlorophyll fluorescence response values among aphid treatments strongly suggests that aphid feeding was not associated with photoinhibitory damage in the PSII reaction centers.

Infested-susceptible plants had $\mathrm{Y}$ values similar to those of control plants on days 1,3 , and 6 , but by day $10, \mathrm{Y}$ values were lower than control plants (Infested: $0.08 \pm 0.03$; Control: $0.21 \pm 0.02$ ). Over the course of the experiment, infested-resistant plants had $\mathrm{Y}$ values similar to control plants. $\mathrm{Y}$ is a good indication of how efficiently absorbed photons are converted into chemical products (Malkin and Niyogi 2000). Our results show that aphid feeding may play a role in the efficiency of converting photons to chemical products in the susceptible barley.

There was a significant aphid by day interaction for the photochemical fluorescence quenching (qP) $(F=4.2$; df $=3,48 ; P=0.001)$ and non-photochemcial fluorescence quenching $(\mathrm{qN})(F=2.7 ; \mathrm{df}=3,48 ; P=0.05)$ (Table 2). However, quenching coefficient values between aphid treatments of interest were either not significantly different or did not follow an apparent trend.

Similar to those of Macedo et al. (2009), Franzen et al. (2007), and Macedo et al. (2003), our findings provide further evidence that chlorophyll may not be directly impacted by aphid injury, but rather that the carbon fixation reactions of photosynthesis may be more immediately impacted.

\section{Integrated responses}

Over the course of the experiment there was a decline in photosynthetic capacity for both barley genotypes. On days 3 and 6, resistant and susceptible plants experienced similar declines in photosynthesis in response to $D$. noxia feeding (Figs. 1 and 2). However on day 10, resistant and susceptible plants appeared to respond differently to $D$. noxia feeding (Fig. 3). At 10 days after aphid introduction resistant plants exhibited photosynthetic rates similar to those of control plants. In contrast, susceptible-infested plants had photosynthetic rates significantly lower than those of control plants. Differences observed in carbon assimilation curves and gas-exchange parameters,

Table 2 Mean \pm SE of chlorophyll fluorescence responses of resistant and susceptible barley at 1, 3, 6, and 10 days after exposure to $D$. noxia Mean \pm SE

\begin{tabular}{|c|c|c|c|c|c|c|}
\hline & \multicolumn{3}{|l|}{$\mathrm{qP}^{\mathrm{a}}$} & \multicolumn{3}{|l|}{$\mathrm{qN}^{\mathrm{b}}$} \\
\hline & Control & RWA & $P$ value & Control & RWA & $P$ value \\
\hline \multicolumn{7}{|l|}{ Day 1} \\
\hline Susceptible & $0.78 \pm 0.05$ & $1.22 \pm 0.10$ & 0.006 & $0.30 \pm 0.08$ & $0.41 \pm 0.05$ & 0.09 \\
\hline Resistant & $0.76 \pm 0.03$ & $0.58 \pm 0.26$ & 0.25 & $0.82 \pm 0.05$ & $0.31 \pm 0.07$ & 0.0003 \\
\hline \multicolumn{7}{|l|}{ Day 3} \\
\hline Susceptible & $1.21 \pm 0.04$ & $0.91 \pm 0.06$ & 0.03 & $0.36 \pm 0.04$ & $0.30 \pm 0.07$ & 0.41 \\
\hline Resistant & $1.05 \pm 0.06$ & $1.45 \pm 0.04$ & 0.004 & $0.40 \pm 0.03$ & $0.36 \pm 0.06$ & 0.50 \\
\hline \multicolumn{7}{|l|}{ Day 6} \\
\hline Susceptible & $0.98 \pm 0.06$ & $0.97 \pm 0.04$ & 0.93 & $0.45 \pm 0.04$ & $0.47 \pm 0.08$ & 0.74 \\
\hline Resistant & $0.88 \pm 0.07$ & $1.40 \pm 0.07$ & 0.001 & $0.49 \pm 0.03$ & $0.45 \pm 0.09$ & 0.53 \\
\hline \multicolumn{7}{|l|}{ Day 10} \\
\hline Susceptible & $0.93 \pm 0.09$ & $0.72 \pm 0.17$ & 0.13 & $0.33 \pm 0.02$ & $0.27 \pm 0.07$ & 0.45 \\
\hline Resistant & $0.54 \pm 0.03$ & $0.92 \pm 0.16$ & 0.01 & $0.07 \pm 0.06$ & $0.27 \pm 0.08$ & 0.001 \\
\hline
\end{tabular}

${ }^{\mathrm{a}} q P$ Photochemical quenching $\left(\mathrm{F}_{\mathrm{m}}-\mathrm{F}_{\mathrm{s}}\right) /\left(\mathrm{F}_{\mathrm{ms}}-\mathrm{F}_{\mathrm{o}}\right)$

${ }^{\mathrm{b}} q N$ Non-photochemical quenching $\left(\mathrm{F}_{\mathrm{m}}-\mathrm{F}_{\mathrm{ms}}\right) /\left(\mathrm{F}_{\mathrm{m}}-\mathrm{F}_{\mathrm{o}}\right)$ 
specifically, $\mathrm{J}_{\max }, \mathrm{A}_{\max }, \mathrm{V}_{\mathrm{cmax}}$, and $\mathrm{CE}$, between control and infested plants show that $D$. noxia feeding negatively impacts the carbon-linked/dark reactions, specifically rubisco activity and RuBP regeneration, in susceptible barley. These reductions are consistent with photosynthetic reductions resulting from limitation in fixation.

The ability of the resistant-infested plants to compensate for aphid pressure and maintain levels of photosynthesis similar to control plants may be attributed to the resistant plant's ability to maintain normal levels of RuBP regeneration and rubisco carboxylation. However, by 13 days after aphid introduction, infested plants of both barley cultivars had photosynthetic rates significantly lower than those of controls (Fig. 4). By this point in the experiment aphid populations reached levels that overwhelmed the barley seedlings. Photosynthetic rates also declined for control plants by 13 days after aphid introduction (Fig. 4). This decline is likely due to senescence of the measured leaf blade over time.

Results documented in this study compare favorably with those of Franzen et al. (2007). Analysis of the A- $C_{i}$ curves from Franzen et al. (2007) and this study suggests that an increase in rubisco carboxylation and RuBP regeneration in the resistant plants is the source of photosynthetic compensation. This study also demonstrates that short-term changes in photosynthetic compensation can be used to differentiate between resistant and susceptible genotypes. Additional studies are needed to determine the degree to which photosystems I and II are affected by aphid injury and the role of photosynthetic compensation in the tolerant barley.

Acknowledgements We gratefully acknowledge Blair Siegfried for reviewing this manuscript. We also thank Gary Hein and Frank Peairs for plant material. This research was supported in part by the University of Nebraska Agriculture Experiment Station Projects 17-078 and $17-080$.

\section{References}

Burd JD, Burton RL (1992) Characterization of plant damage caused by Russian wheat aphid. J Econ Entomol 85:2017-2022

Burd JD, Elliott NC (1996) Changes in chlorophyll $a$ fluorescence induction kinetics in cereals infested with Russian wheat aphid (Homoptera: Aphididae). J Econ Entomol 89:1332-1337

Farquhar GD, Sharkey TD (1982) Stomatal conductance and photosynthesis. Annu Rev Plant Physiol 33:317-345. doi:10.1146/ annurev.pp.33.060182.001533

Franzen LD, Gutsche AR, Heng-Moss TM et al (2007) Physiological and biochemical responses of resistant and susceptible wheat to injury by the Russian wheat aphid, Diuraphis noxia (Mordvilko). J Econ Entomol 100:1692-1703. doi:10.1603/0022-0493(2007) 100[1692:PABROR]2.0.CO;2

Haile FJ, Higley LG, Ni X et al (1999) Physiological and growth tolerance in wheat to Russian wheat aphid (Homoptera: Aphididae) injury. Environ Entomol 28:787-794
Heng-Moss TM, Ni X, Macedo T et al (2003) Comparison of chlorophyll and carotenoid concentrations amoung Russian wheat aphid (Homoptera: Aphididae)-infested wheat isolines. J Econ Entomol 96:475-481

Macedo TB, Higley LG, Ni X et al (2003) Light activation of Russian wheat aphid-elicited physiological responses in susceptible wheat. J Econ Entomol 96:194-201

Macedo TB, Peterson RKD, Weaver DK et al (2009) Impact of Diuraphis noxia and Rhopalosiphum padi (Hemiptera: Aphididae) on primary physiology of four near-isogenic wheat lines. J Econ Entomol 102:412-421. doi:10.1603/029.102.0154

Malkin R, Niyogi K (2000) Photosynthesis. In: Buchanan B, Gruissem W, Jones R (eds) Biochemistry and molecular biology of plants. American Society of Plant Physiologists, Rockville, MD, pp 568-628

Miller H, Porter DR, Burd JD et al (1994) Physiological effects of Russian wheat aphid (Homoptera: Aphididae) on resistant and susceptible barley. J Econ Entomol 87:493-499

Mornhinweg DW, Porter DR, Webster JA (1995) Registration of STARS-9301B barley germplasm resistant to Russian wheat aphid. Crop Sci 35:602

Mornhinweg DW, Porter DR, Webster JA (1999) Registration of STARS-9577B Russian wheat aphid resistant barley germplasm. Crop Sci 39:882

Mornhinweg DW, Obert DE, Wesenberg D, Erickson CA, Porter DR (2006) Registration of seven winter feed barley germplasm lines resistant to Russian wheat aphid. Crop Sci 46:1826-1827

Mornhinweg DW, Bregitzer PP, Porter DR (2007a) Registration of nineteen spring six-rowed barley germplasm lines resistant to Russian wheat aphid. J Plant Regist 1:137-138. doi:10.3198/ jpr2006.12.0815crg

Mornhinweg DW, Bregitzer PP, Porter DR (2007b) Registration of seventeen spring two-rowed barley germplasm lines resistant to Russian wheat aphid. J Plant Regist 1:135-136. doi:10.3198/ jpr2006.12.0814crg

Mornhinweg DW, Bregitzer PP, Porter DR (2008) Registration of seven spring two-rowed barley germplasm lines resistant to Russian wheat aphid. J Plant Regist 2:230-234. doi:10.3198/ jpr2007.12.0716crg

Ni X, Quisenberry SS, Heng-Moss T et al (2002) Dynamic change in photosynthetic pigments and chlorophyll degradation elicited by cereal aphid feeding. Entomol Exp Appl 105:43-53. doi: 10.1023/A:1021754831841

Pons L (2004) Germplasm from previous study may thwart new aphid biotype. Agricultural Research, USDA-ARS, April 2004, pp 1618

Rafi MM, Zemetra RS, Quisenberry SS (1996) Interaction between Russian wheat aphid (Homoptera: Aphididae) and resistant and susceptible genotypes of wheat. J Econ Entomol 89:239-246

Rafi M, Zemetra M, Quisenberry SS (1997) Feeding damage of Russian wheat aphid on resistant and susceptible wheat genotypes. Cereal Res Commun 25:63-68

Ryan JD, Johnson RC, Eikenbary RD, Dorschner KW (1987) Drought/greebug interactions: photosynthesis of greenbug resistant and susceptible wheat. Crop Sci 27:283-288

SAS Institute (2002) PROC user's manual, version 9.1. SAS Institute, Cary, NC

Webster JA, Kenkel P (1999) Benefits of managing small-grain pests with plant resistance. In: Wiseman BR, Webster JA (eds) Proceedings, Thomas Say Publications in entomology. Entomological Society of America, Lanham, MD, pp 87-114 